\title{
APRISIONAMENTO PSÍQUICO NAS ORGANIZAÇÕES: DO MITO À REALIDADE
}

\author{
PSYCHIC TRAPPING IN ORGANIZATIONS: FROM MYTH TO REALITY
}

\author{
Maria Claudete Silva ${ }^{1}$ \\ Laura Silva Campos Lessa ${ }^{2}$
}

\begin{abstract}
Resumo: Esse artigo busca explicitar um modelo de defesa que trabalhadores utilizam para permanecerem por muitos anos em uma organização partindo da categoria do mito Golem Laborioso, proposto por Thiry-Cherques (2004). Esse modelo representa uma forma de adesão total dos trabalhadores ao sistema, onde vida e sistema se confundem. Buscou-se uma abordagem qualitativa, a partir de estudo de casos múltiplos com oito profissionais em cargo de gestão que trabalham no contexto pesquisado há mais de 15 anos. Os dados foram coletados com entrevistas semiestruturadas, técnicas projetivas e observação direta, o que tornou possível a identificação e classificação dos casos estudados de acordo com o modelo proposto. Os resultados evidenciaram que o trabalho tem uma importância vital na vida das pessoas, que elas não são livres e ficam aprisionadas psiquicamente dentro das próprias armadilhas que criam para se manterem nas suas atividades laborais, pois ficar sem emprego é perder o sentido da vida. Como forma de garantir a subsistência material e sobreviver às pressões impostas no dia a dia, as pessoas acabam desenvolvendo, de forma inconsciente, modelos de defesa.
\end{abstract}

Palavras-Chave: Trabalho. Mito. Sobrevivência. Aprisionamento.

Abstract: This article looks there set the model of defense out which workers use to remain for many years in an organization, in the category myth Golem Laborioso. A qualitative approach was looked, from study of multiple cases with eight professionals in post of management who work in the context investigated more than 15 years ago. The data base were collected with semistructured interviews, projective techniques and straight observation, which made possible the identification and classification of the cases studied in accordance with the proposed models, being six in the category of Golem Laborioso, proposed by Thiry-Cherques (2004). This model represents the form of total adhesion of the workers to the system, where it plants vines and they confuse system. The results showed up that the work is

\footnotetext{
${ }^{1}$ Discente do Programa de Doutorado em Psicologia da Universidade Federal do Rio de Janeiro PPGP/UFRJ. claudete.silva1@hotmail.com.

2 Discente da Graduação em Psicologia da Universidade Federal do Rio de Janeiro. laurasclessa@gmail.com.
} 
vitally important in the life of the persons, which they are not free and are imprisoned inside the traps themselves that were believing to support themselves in his activities you labor, since it will be left without job it is to lose the sense of the life. Like the form of guaranteeing the material subsistence and of surviving the pressures imposed in day by day, the persons finish developing, in the unconscious form, models of defense.

Keywords: Work. Myth. Survival. Psychic trapping. 


\section{INTRODUÇÃO}

Uma das grandes preocupações da área de recursos humanos é reter pessoas, mas isso se dá sem levar em conta o papel da subjetividade dos trabalhadores.

Segundo estudo realizado pelo Departamento Intersindical de Estatística e Estudos Socioeconômicos (Dieese), o tempo médio de permanência do brasileiro no emprego foi de 5,5 e 5,0 anos, respectivamente. O estudo também aponta elevadas taxas de rotatividade - 45\% em 2001 e 54\% em 2010 -, o que indica um aumento de nove pontos percentuais. Esse alto valor envolve vários custos para a organização.

Identificar de que forma as pessoas sobrevivem por longos períodos em uma organização traz uma nova perspectiva dos vínculos que trabalhadores estabelecem com as empresas nas quais são admitidos. Busca compreender a produção de novos modos de ser e desvendar a face íntima do ser humano, naquilo que não é por ele declarado, e como essa parte inconsciente influencia nas atitudes, no engajamento e em sua mobilização nas organizações.

As exigências que são impostas às pessoas, no mundo contemporâneo, desencadeiam a reflexão acerca da dimensão humana que parece, às vezes, ficar esquecida no mundo dos negócios.

É preciso reconhecer que cada um constrói suas narrativas na manutenção dos vínculos que estabelece com a organização, das quais se pode apreender o porquê de fenômenos fundamentais para a gestão de pessoas. Afinal, os seres humanos criam suas próprias histórias de vida e a vivem como prisioneiros das tramas pessoais que eles mesmos desenvolvem.

Percebe-se que sobreviver a todo o dilema que o trabalho proporciona é difícil e traz sofrimento, mas o pior é o desemprego. Assim, para manterem seus empregos, as pessoas acabam aceitando realizar tarefas repetitivas, perigosas ou sem sentido (THIRY-CHERQUES, 2004).

Tal submissão, somada à forma de sobreviver a todas as pressões que o mundo contemporâneo proporciona dentro das organizações, é o modo que os 
indivíduos encontram de permanecerem ativos e, de certa forma, sanar suas necessidades pessoais, sociais e psicológicas.

Para satisfazer a essas necessidades, que são sanadas à medida que é estabelecido o vínculo entre organização e trabalhador, o indivíduo busca uma estratégia de sobrevivência que o preserve dentro da empresa.

Thiry-Cherques (2004), baseado em pesquisas empíricas, realizadas em organizações brasileiras, relata que os trabalhadores, na tentativa de manterem esse vínculo com a organização, o autocontrole e para preservarem-se, desenvolvem modelos de sobrevivência para as exigências do cenário contemporâneo. O referido autor traçou um paralelo entre personagens da mitologia e atitudes que trabalhadores apresentam como forma de sobreviverem nas empresas.

Sobreviver no mito é a forma encontrada que trabalhadores utilizam no seu dia a dia para afastarem o fantasma de ficar sem o trabalho assalariado num mundo de mudanças contínuas e de inovações tecnológicas, que surgem cotidianamente, e da própria relação que estabelecem na tentativa de tornarem seus ofícios prazerosos, já que "o mito utiliza uma variedade de significantes, que têm como objetivo exprimir e disfarçar, simultaneamente, os desejos e as angústias." (ENRIQUEZ, 1997, p. 46).

Este artigo busca relatar o primeiro modelo que Thiry-Cherques (2004) apresenta - o Golem Laborioso, pois foi o mais identificado na pesquisa realizada, com gestores em uma clínica prestadora de serviço em hemodiálise, cujo comportamento identificado é o de um trabalhador completamente alienado ao trabalho, mas não vive sem ele. Pessoas que se sujeitam as condições do sistema e que recusam-se a ver as opressões do sistema, perdendo o sentido da própria vida, pois vida e sistema se fundem.

Pretende, ainda, contribuir para se pensar que as organizações devem levar em consideração aspectos além dos estritamente racionais. Dessa forma, aspira a sensibilizá-las, a fim de que elas não tenham um caráter meramente racional e possam lidar com as idiossincrasias humanas.

\section{CONSIDERAÇÕES TEÓRICAS}




\title{
2.1 Subjetividade no trabalho e aprisionamento psíquico
}

O trabalho é considerado parte da condição humana, visto que, em sua centralidade, desempenha papel fundamental para realização das pessoas, pois é por meio dele que a maioria das relações entre os homens se estabelece.

Dessa forma, em qualquer sociedade ou época histórica, é pelo trabalho que o homem se relaciona com a natureza e com o outro, criando condições necessárias para a produção, reprodução e transformação da vida humana.

Nessa perspectiva, o trabalho não pode ser considerado tão somente um emprego, mas sim um recurso que servirá como uma forma para o indivíduo construir um significado de si mesmo, para si mesmo e/ou para outros (BENDASSOLLI, 2011). Sua amplitude é maior do que a de execução de uma tarefa; é uma atividade humana vital, que garante o desenvolvimento e a existência da vida individual e da sociedade.

Dentro desse contexto, pode ser considerado uma das atividades que representa uma possibilidade de vínculos entre as pessoas. Freud (1974) argumenta que:

\begin{abstract}
Nenhuma outra técnica para a conduta da vida prende o indivíduo tão fortemente à realidade quanto a ênfase concedida ao trabalho, pois este, pelo menos, fornece-lhe um lugar seguro numa parte da realidade, na comunidade humana. A possibilidade que essa técnica oferece de deslocar uma grande quantidade de componentes libidinais, sejam eles narcísicos, agressivos ou eróticos, para o trabalho profissional, e para os relacionamentos humanos a ele vinculados, empresta-lhe um valor que de maneira alguma está em segundo plano quanto ao de que se goza como algo indispensável à preservação e justificação da existência em sociedade (FREUD, 1974, p. 99).
\end{abstract}

Assim, a organização passa a ser para as pessoas uma realidade inconteste, onde elas têm a possibilidade de viver e realizar seus desejos de afiliação. Vão se apegando a seus trabalhos de modo exclusivo, como forma de garantir sua própria existência (ENRIQUEZ, 1997). 
Reiterando Enriquez (1997), Pagès e outros (2006) relatam que as pessoas ligam-se à organização não apenas por alianças materiais, morais, econômicas e ideológicas, mas também por laços psicológicos e sociais.

Pode-se afirmar que o trabalho assume papel medular na vida das pessoas, que acabam por construí-la em torno da atividade laboral. A ideia de que o trabalho enobrece o homem está cada dia mais presente no consciente humano, e, também, no inconsciente. Muitas vezes, exclui - ou relega a segundo plano - dimensões importantes da vida do homem, como o lazer e o prazer.

Percebe-se, assim, que o trabalho não está limitado ao tempo físico efetivamente passado dentro das organizações - como se acredita frequentemente. Ele ultrapassa qualquer limite dispensado ao tempo da carga horária; ele mobiliza a vida das pessoas como um todo, mesmo quando estão fora da empresa.

De acordo com Freitas (2000), as organizações vêm ganhando cada vez mais relevância e destaque no cotidiano dos indivíduos e as relações estabelecidas no contexto organizacional tendem a monopolizar a sua vida social. A autora constata que o trabalho é uma fonte de referência para a construção social do homem e de sua autoestima, o que significa que essa relação passa pelo afetivo e pelo psicológico.

Por isso, "o trabalho não é, em primeira instância, a relação salarial ou o emprego; é o trabalhar, isto é, certo modo de engajamento da personalidade para responder a uma tarefa delimitada por pressões materiais e sociais." (DEJOURS, 2004, p. 28).

Nesse sentido, Giddens (apud Viana, 2008, p. 306) afirma que:

Nas sociedades modernas, ter um emprego é importante para manter a auto-estima. Mesmo nos lugares em que as condições de trabalho são relativamente desagradáveis, e as tarefas monótonas, o trabalho tende a representar um elemento estruturador na composição psicológica das pessoas e no ciclo de suas atividades diárias.

Esses autores apontam a forma central que o trabalho ocupa na vida das pessoas, pois trabalhar influencia a manifestação da subjetividade dos indivíduos. 
A subjetividade pode ser vista como constituída a partir da experiência social: (a) sujeito da enunciação como agente que interioriza uma diversidade de regras lingüísticas convencionais, podendo assim atribuir e interpretar diferentes significados em diferentes contextos; (b) sujeito como representação ideológica mínima significativa da vida social, isto é, o indivíduo; (c) sujeito privatizado que, a partir da Idade Moderna, passa a ter uma esfera privada de existência - lugar da intimidade e da emoção - situada nas relações amorosas, familiares e de amizade, esfera esta que se contrapõe a uma esfera pública de desempenho de papéis sociais e profissionais; e (d) sujeito psicológico, em que a referência privilegiada tornou-se, na sociedade contemporânea, a sexualidade como meio de tomar consciência de si próprio; a 'verdade' do indivíduo é, então, o seu 'desejo' (COUTINHO, 1985 apud DAVEL; VERGARA, 2006, p. 43).

Pensar na influência que o trabalho ocasiona na formação da subjetividade é levar em consideração o homem como: corpo, pensamento, afeto e ação. A configuração dessa subjetividade é um processo único, que surge da unidade dialética entre o sujeito e o meio social, que vai definir a forma singular e individual que cada pessoa vai se constituindo e se desenvolvendo, de acordo com as experiências da vida social e cultural.

Para Rey (2003), a subjetividade não é algo dado, que a priori determina o curso das ações humanas. Para compreender seu processo de configuração, há necessidade de se considerar a dialética "subjetividade individual" e "subjetividade social". Para o autor, a subjetividade é:

uma dimensão presente em todos os fenômenos da cultura, da sociedade e do homem (...) [estando] constituída tanto no sujeito individual, como nos espaços sociais em que este vive, sendo ambos constituintes da subjetividade. O caráter relacional e institucional da vida humana implica a configuração subjetiva não apenas do sujeito e de seus diversos momentos interativos, mas também dos espaços sociais em que essas relações são produzidas. Os diferentes espaços de uma sociedade concreta estão estreitamente relacionados entre si em suas implicações subjetivas. É nesse nível de organização da subjetividade que denominamos subjetividade social.

A subjetividade social apresenta-se nas representações sociais, nos mitos, nas crenças, na moral, na sexualidade, nos diferentes espaços que vivemos etc. e está atravessada pelos discursos e produções de sentidos que configuram sua organização subjetiva. 
Cada uma das formas de expressão da subjetividade social expressa a síntese, em nível simbólico e de sentido subjetivo, do conjunto de aspectos objetivos, macro e micro, que se articulam no funcionamento social. Esses são os mesmos elementos que se articulam na formação da subjetividade individual, com a diferença que os processos de sentido nesse nível estão constituídos, de maneira diferenciada, pelos aspectos singulares da história das pessoas concretas (REY, 2005, p. 22-24).

Nesse sentido, é necessário compreender a subjetividade como um sistema complexo, que possui dois espaços de constituição: o individual e o social. A subjetividade individual permite a elaboração de produções específicas e singulares, diante dos diferentes contextos da subjetividade social (REY, 2004).

Assim, a subjetividade social está na gênese da subjetividade individual; uma e outra são contraditórias e integram-se na constituição complexa da subjetividade humana, que é inseparável da condição social do homem.

É importante destacar que as organizações, dos pontos de vista social e cultural, não são apenas locais onde os trabalhos são executados. São espaços de experiência social, que vão interferir na formação de cada trabalhador; são também lugares onde os pesadelos, desejos, a excitação e o prazer da conquista convivem com a angústia e o fracasso.

Portanto, considerar a subjetividade nas empresas é pensar que as pessoas estão em permanente interação, dotadas de vida interior, que expressam sua subjetividade por meio de palavras e de comportamentos não verbais. Segundo Coutinho citado por Davel e Vergara (2006),

A linguagem controla e estrutura as possibilidades de ação das pessoas. Se a linguagem é o veículo privilegiado da subjetividade, a vida psíquica é seu fundamento. O ser humano, ser de desejo e de pulsão, como define a psicanálise, é dotado de uma vida interior, fruto de sua história pessoal e social (COUTINHO apud DAVEL; VERGARA, 2006, p. 50).

Morgan (1996) lança mão da metáfora da prisão psíquica como forma de ilustrar uma inclinação especial do ser humano para cair em armadilhas do seu próprio pensamento, de suas crenças ou preocupações. 
Para desenvolver sua metáfora, Morgan baseia-se em Platão, que desenvolveu uma parábola, conhecida como a Alegoria da Caverna. O filósofo a desenvolve a partir de uma caverna subterrânea onde vivem algumas pessoas acorrentadas e, em sua entrada, encontra-se uma fogueira. Como seus habitantes estão de costas para a saída, tudo o que enxergam são as sombras das pessoas e objetos projetados pelo fogo, de tal modo que essas visões são a única realidade para eles.

A verdade e a realidade são constituídas por um universo sombrio e restrito, já que não possuem conhecimento de outro mundo.

A alegoria mostra uma caverna subterrânea, cuja entrada se acha voltada para uma fogueira crepitante. Dentro dela encontram-se pessoas acorrentadas, de tal modo que não possam mover-se. Conseguem enxergar somente a parede da caverna diretamente à sua frente. Esta parede é iluminada pela claridade das chamas que nela projetam sombras de pessoas e objetos (MORGAN, 1996, p.205).

Uma das pessoas desfaz suas amarras e consegue sair. Com a descoberta de uma nova realidade fora da caverna, o retorno seria inaceitável para quem vivenciou o novo mundo e uma ameaça para aqueles que continuaram no confinamento.

Ao regressar à caverna, aquele que saiu tenta contar sua experiência para os demais, que, entretanto, não o compreendem e muito menos aceitam essa nova visão. Existe o risco, inclusive, de que essa pessoa seja excluída do grupo.

Algumas organizações e seus membros desenvolvem culturas que aprisionam a forma de ver e lidar com o mundo, atualizando o universo obscuro da Alegoria da Caverna. Sob a égide do pragmatismo e da objetivação do saber, surgem visões estreitas do mundo, pressupostos falsos, crenças estabelecidas, regras operacionais sem questionamento - além de numerosas outras premissas e práticas limitadoras.

Nesse contexto, a organização possibilita a emergência do saber inconsciente, saber que designa o conjunto de determinações que regem a vida de um sujeito e que, contraditoriamente, escapam a ele. A busca pela plenitude é 
atualizada nas relações estabelecidas dentro da organização e com o próprio envolvimento com o trabalho.

Dessa forma, as práticas organizacionais agem de forma a transformar as identidades e o sentido do trabalho e essa transformação visa "fabricar os tipos 'certos' de indivíduos, aqueles com as atitudes e as predisposições necessárias para desempenhar os papéis exigidos pela organização" (COSTA, 2003, p. 50).

O trabalho realizado dentro de uma organização assume uma importância expressiva na vida do indivíduo e em suas histórias pessoais e sociais. Seu desaparecimento rompe um laço vital da própria existência humana. O trabalho proporciona ao homem a segurança de se sentir parte das formações sociais. Por isso, luta-se tanto para sobreviver a ele (THIRY-CHERQUES, 2004).

A realidade das organizações é complexa, mas pode ser abordada e interpretada por meio de perspectivas múltiplas e complementares. Assim, selecionar figuras míticas e encontrar em cada uma delas meios que os trabalhadores utilizam para manter o autocontrole nas empresas é tornar possível a identificação de um conjunto de pessoas que apresentam condutas semelhantes como forma de sobreviverem nas organizações.

\subsection{Mito}

O conceito de mito tem constituído ponto de controvérsia entre os teóricos, desde a Antiguidade, até os dias atuais. Em meio a uma série de posições, destacam-se, grosso modo, duas concepções: uma vê o mito como fruto da ignorância e fonte de escravização do homem; outra o considera raiz de sabedoria.

As explicações para a origem dos mitos variam de acordo com a área de estudo em questão; porém, todas as ciências têm um ponto em comum: "Os mitos sempre contêm símbolos de sentido oculto ou manifesto, que tentam aplacar os temores e ansiedades humanas, frente ao inexplicável” (MENDES, 1994, p. 11).

Segundo Enriquez (1997, p. 41),

os mitos, quaisquer que sejam as diferentes versões que nos chegam e que testemunham a espessura histórica na qual eles têm atuado e são trabalhados, colocam-se ao nível da meta-história ou, 
com mais exatidão, provêm da trans-história; na medida mesma em que eles relatam acontecimentos de natureza acidental, ou devendo sobrevir a seres fora do comum (os Deuses, os Antepassados, os Heróis), num tempo primordial. Esse texto sem autor permite aos homens encontrarem um ponto de ancoragem ultramundano e os mergulha diretamente no tempo humano (irreversível), o da história, do drama, do confronto louco com a vida e a morte. Narrativa sem data de acontecimentos pontuais, no exterior da história e abrindo-se à história: tais são os paradoxos do mito.

Nesse contexto, os mitos são narrativas cheias de simbologia, que visam explicar fatos da realidade, fenômenos da natureza, as origens do mundo e do homem que, muitas vezes, não podem ser compreendidos.

Segundo Enriquez (1997, p. 44), o mito pode se apresentar como:
comunicação afetiva e sistema conceitual, como suporte indispensável à criação de um grupo. Ele tem por função unificar os pensamentos e os comportamentos, evocar as ações e convidar à ação. [...] Mas na qualidade de criador de grupo, ele combate a desordem, a inovação, a revolta.

Esse autor afirma que existir no mito é a forma de aceitar viver no mundo da comunidade, do grupo e, dessa forma, partilhar os fantasmas existentes em cada ser humano, pois o mito permite cada indivíduo se aceitar como indivíduo social.

Assim, o mito deve ser interpretado tal como os sonhos, pois se apresenta como a tradução dos fantasmas individuais e coletivos que possibilita a existência, uma vez que, sem o mito, nenhuma civilização e nenhum indivíduo poderiam sobreviver.

Segundo Eliade (2013), o mito é uma realidade cultural complexa, que pode ser abordada e interpretada por meio de perspectivas múltiplas e complementares. Os mitos vêm carregados de algo oculto e são mantidos graças a crenças individuais que as pessoas legitimam, para não serem questionadas sobre determinado assunto. Assim, os mitos recebem o status de verdade.

No entanto, como destaca Thiry-Cherques (2000), o mito não é uma mentira, pois sua existência se faz necessária para o ser humano ter uma explicação sobre o acontecer da vida e para que o mundo faça sentido. 
Para quem vive o mito, ele é a única história verdadeira, proposta numa linguagem acessível ao mundo, às coisas e ao homem. Os mitos reproduzem gestos criadores e significativos, que permanecem sustentando a realidade constituída.

Isso ocorre porque o mito desempenha uma função social, ou seja, determinado grupo de pessoas une-se e tem no mito o principal ponto de interação. Sua função não é, primordialmente, explicar a realidade, mas acomodar e tranquilizar o homem.

\subsection{Golem Laborioso}

O Golem é um dos mais fascinantes mitos judeus. É feito de barro, à imagem do homem, tendo como propósitos a proteção da comunidade judaica e a realização de trabalhos braçais. É um ser mítico, associado à tradição mística do judaísmo, particularmente à cabala, que pode ser trazido à vida através de um processo que não possui explicação racional - a força da palavra mágica, o emet, que cria e destrói o ser artificial.

Durante o Renascimento, a lenda do Golem assumiu um aspecto diferente, pois ele se destinava a ser uma utilidade doméstica e tornava-se o servo dos homens, cumprindo suas tarefas com maior facilidade.

Segundo Meyrink, (2003, p. 8), o Golem não se trata somente da transposição de uma antiga lenda:

pelo seu fundamental pessimismo, sua atmosfera repleta de equívocos contínuos, seus resquícios de crueldade e pavor, pode ser considerado sobretudo uma descrição perturbada da condição do homem dentro da sociedade moderna: individuo mecanizado, quase transformado num produto de consumo, como mercadoria que pode ser usada e abusada.

Assim, à luz da modernidade, poder-se-ia comparar o Golem a um autômato, um robô.

Nas organizações contemporâneas, o modelo de sobrevivência apoiado na figura do Golem Laborioso é aquele profissional que não separa a vida pessoal da vida do trabalho e que, para sobreviver, prefere se avassalar ao sistema. É o 
trabalhador que não se rebela, aliena-se dos resultados, do controle e, com frequência, da compreensão dos processos produtivos, desenvolvendo uma conduta de aceitação e conformismo por natureza ou por estratégia de subsistência. Seus relacionamentos interpessoais acabam por formar uma rede social profissional que, muitas vezes, se torna parte de sua vida pessoal. São trabalhadores que renunciam à individualidade, para quem o trabalho é refúgio e garantia de um porto seguro contra as intempéries da existência. Trabalhadores absolutos que, como fórmula de sobrevivência, toleram ou constroem uma agenda de reciprocidade em que a vida é refém do sistema e o sistema afiança a vida.

Para Thiry-Cherques (2000), são duas as circunstâncias que levam à constituição desse modelo: a mentalidade de gueto e o desejo de pertencer.

A primeira deriva da sujeição como condição da existência, da insensibilidade e da recusa em ver as opressões do sistema. Ou seja, são trabalhadores que alienam a vida ao sistema e, assim, perdem cada vez mais o sentido da própria vida.

A segunda, o desejo de pertencer, é proveniente da convicção ou da sensação de que a individualidade só existe como parte de algo maior, pois toda a perspectiva de vida está limitada a pertencer não a um grupo, mas a uma organização.

Assim, “a perspectiva de vida está limitada ao pertencimento. Dá-se a transferência da necessidade de pertencer a um grupo para a necessidade de pertencer a uma organização, de se alienar integralmente ao sistema." (THIRYCHERQUES, 2004, p. 27).

Essas circunstâncias dão a ideia de que cada um de nós é o que é somente em relação aos outros, aos grupos, às instituições, às organizações. As mudanças tecnológicas, a perda do emprego, a aposentadoria são vistas como fatores assustadores para os trabalhadores que se adéquam a esse modelo.

Segundo Thiry-Cherques (2000, p. 220), dentre os traços de conduta típicos desse modelo, encontra-se:

Em primeiro lugar, a desconfiança e a aversão a tudo que possa ameaçar o sistema tal como estabelecido. Um agravo à estabilidade do sistema costuma ser interpretado como ataque aos valores da vida. 
Em segundo lugar, como decorrência desse primeiro traço, a limitação dos horizontes. Os que se ajustam ao modelo tendem a ater-se ao imediato, a desempenhar o papel que melhor se encaixe nas necessidades de manutenção do sistema.

Em terceiro lugar, é a aceitação, a conformidade das imposições do sistema. De forma que não só o corpo, a sobrevivência material, mas também o espírito, a sobrevivência da individualidade, se confundem com as possibilidades e vicissitudes do sistema.

Essas características nada mais são do que posicionamentos que alguns trabalhadores encontram como forma de garantirem sua sobrevivência no sistema. $O$ trabalho funciona, para eles, como um elo entre a vida e o sistema, uma garantia, um porto seguro.

Esse modelo é uma forma de adesão total ao sistema, que se confunde com a vida. Os valores da organização são adotados pelos indivíduos na sua vida particular, ou seja, "os valores do sistema já não são apenas considerados, eles foram absorvidos. De tal sorte que passaram a ocupar o lugar dos valores culturais e espirituais no mundo da vida." (THIRY-CHERQUES, 2000, p. 222).

Com a impossibilidade de escapar do sistema, algumas pessoas preferem a adesão, na ilusão de troca com a organização, pois, assim, o trabalhador é tanto vítima como beneficiário dessa estrutura, encontrando conforto e segurança.

"Mas o estar ou ter sido iludido é uma circunstância. Uma circunstância a que as pessoas cujo perfil se aproxima do de um androide se rendem, ou abraçam, inconscientemente." (THIRY-CHERQUES, 2004, p. 42).

Nesse modelo, as categorias que se apresentam são:

- Vida e sistema - Não há vida fora do sistema; as pessoas tendem a não separar sua vida social da profissional, existindo uma união e adesão, na qual ambas são indivisíveis.

- Mundo do sistema - O sistema é que dá sentido à vida, levando as pessoas a terem um certo orgulho de fazerem parte dele, sentirem-se protegidas; a organização apresenta-se como um porto seguro.

- Sobrevivência - A sobrevivência é garantida para os trabalhadores que se integram e se identificam como inseridos no sistema, ou seja, fazem parte 
de tal forma a sacrificar-se, dedicar-se e adequar-se às exigências que lhe são impostas.

- Traços - Os trabalhadores possuem uma mentalidade de gueto, sujeitando-se como condição da existência e acabam por se comportarem de forma submissa, acomodada, com certa humildade e disponibilidade.

Com base nas categorias do modelo, é possível associar a ele determinadas características que indivíduos apresentam na sua interação com as organizações. São elas: realização, reserva, humildade, cautela, limitação, acomodação, submissão, envolvimento, dedicação, sacrifício, aceitação, compreensão, apego, preocupação, satisfação, conquista, segurança, proteção, orgulho, dependência, necessidade, sustento, adesão e união.

Esse modelo ocorre porque há uma ausência da capacidade crítica dos trabalhadores. Para as organizações, esse modelo não é prejudicial, uma vez que os profissionais agem dentro dos valores aceitos por ela. Em contrapartida, do ponto de vista do trabalhador, a sua individualidade é anulada, já que sua vida se restringe à vida da organização, fazendo dos valores da empresa os seus próprios.

\section{METODOLOGIA}

A pesquisa realizada foi de natureza qualitativa, de caráter descritivo e de campo. Para a coleta de evidências foram utilizados: entrevistas, uso de desenhos, evocação de frases e observação direta que permitiram verificar como a teoria estudada se aplica na vida real.

A estratégia adotada foi a de estudo de casos múltiplos, pois pretendeu obter conhecimento detalhado e aprofundando dos modelos de sobrevivência que os gestores da empresa onde a pesquisa foi realizada desenvolvem para permanecerem por um longo período nesta organização. Optou-se por casos múltiplos em virtude das experiências dos indivíduos serem particulares e relevantes no cargo que ocupam. Dessa forma, foi possível apreender a subjetividade de cada participante de modo a identificar e classificar cada caso dentro do modelo proposto. O estudo dos casos foi realizado de forma simultânea, porém priorizou a 
individualidade de cada participante, no total oito casos, e não a empresa em que atuam.

No que se refere à análise das evidências foi adotada a análise de conteúdo nas entrevistas, uma vez que é considerada uma técnica que visa identificar o que está sendo dito a respeito de determinado tema (VERGARA, 2006). Foi possível verificar não apenas o que os trabalhadores verbalizaram, mas também, a forma, o tom de voz, expressões faciais e corporais associados aos significados que empregam a categoria do Golem laborioso proposta por Thiry-Cherques (2004) como forma de sobreviver na organização.

O uso dos desenhos foi classificado em representações sobre o sujeito, sobre seu trabalho e sobre a organização, o que permitiu a complementação das evidências obtidas. Sua interpretação permitiu resgatar a subjetividade dos indivíduos em dimensões difíceis de serem expressas por meio de palavras, contribuindo, assim, para a triangulação das evidências.

Com relação à evocação de frases, as respostas dadas pelos participantes foram consideradas dentro da categoria do modelo de sobrevivência proposto por Thiry-Cherques (2004), nas quais foram construídos termos que se referiam a cada modelo.

E, por fim, a observação direta proporcionou informações adicionais, que contribuíram para o entendimento do objetivo deste estudo, uma vez que dela tomaram parte pessoas implicadas na situação investigada, tanto pesquisadora como participantes.

\section{OS CASOS ESTUDADOS}

Esta pesquisa selecionou os entrevistados por intencionalidade. Foram entrevistados oito profissionais com nível superior, que foram admitidos na empresa há mais de 12 anos e que ocupam, no momento da pesquisa, cargos de gestão nas áreas de enfermagem e administração. 
Quadro 1 - Perfil dos participantes da pesquisa

\begin{tabular}{|c|c|c|c|c|c|c|}
\hline Casos & Idade & Sexo & $\begin{array}{c}\text { Estado } \\
\text { civil }\end{array}$ & $\begin{array}{l}\text { Formação } \\
\text { Acadêmica }\end{array}$ & $\begin{array}{c}\text { Tempo } \\
\text { de } \\
\text { empresa }\end{array}$ & Cargo atual \\
\hline 1 & 38 & Feminino & Casada & $\begin{array}{c}\text { Superior em } \\
\text { Administração }\end{array}$ & 19 anos & $\begin{array}{l}\text { Encarregada } \\
\text { de Tesouraria }\end{array}$ \\
\hline 2 & 46 & Feminino & Divorciada & $\begin{array}{c}\text { Superior em } \\
\text { Enfermagem } \\
\text { com três } \\
\text { especializações }\end{array}$ & 17 anos & $\begin{array}{c}\text { Gerente Geral } \\
\text { de } \\
\text { Enfermagem }\end{array}$ \\
\hline 3 & 42 & Feminino & Casada & $\begin{array}{l}\text { Superior em } \\
\text { Contabilidade }\end{array}$ & 22 anos & $\begin{array}{c}\text { Chefe de Dep. } \\
\text { Pessoal }\end{array}$ \\
\hline 4 & 49 & Feminino & Solteira & $\begin{array}{c}\text { Superior em } \\
\text { Enfermagem } \\
\text { com uma } \\
\text { especialização }\end{array}$ & 18 anos & $\begin{array}{c}\text { Supervisora de } \\
\text { Enfermagem }\end{array}$ \\
\hline 5 & 37 & Feminino & Casada & $\begin{array}{l}\text { Superior em } \\
\text { Administração }\end{array}$ & 15 anos & Administradora \\
\hline 6 & 40 & Feminino & Casada & $\begin{array}{c}\text { Superior em } \\
\text { Enfermagem } \\
\text { com duas } \\
\text { especializações }\end{array}$ & 16 anos & $\begin{array}{c}\text { Chefe de } \\
\text { Enfermagem }\end{array}$ \\
\hline 7 & 41 & Feminino & Viúva & $\begin{array}{c}\text { Superior em } \\
\text { Enfermagem } \\
\text { com uma } \\
\text { especialização }\end{array}$ & 15 anos & $\begin{array}{c}\text { Chefe de } \\
\text { Enfermagem }\end{array}$ \\
\hline 8 & 45 & Feminino & Casada & $\begin{array}{c}\text { Superior em } \\
\text { Administração } \\
\text { com uma } \\
\text { especialização }\end{array}$ & 19 anos & Administradora \\
\hline
\end{tabular}

Fonte: Elaborado pelos autores

A escolha de tais profissionais foi definida levando-se em consideração algumas razões. Primeiro, por serem empregados da clínica desde a época do hospital e terem sobrevivido ao momento de recessão; segundo, por ocuparem cargos de chefia, o que os leva a serem modelos para seus funcionários; terceiro, por terem nível superior e, na sua maioria, pós-graduação, o que, de certa forma, garantiria uma recolocação no mercado - o que não aconteceu - e a quarta razão seria por estarem acima da média das estatísticas que indicam o tempo médio de permanência dos trabalhadores em uma organização. 


\section{ANÁLISE DOS CASOS}

Ficou evidenciado, dois oito casos estudados, seis como Golem Laborioso, no que diz respeita à relação vida-sistema os entrevistados percebem que não há vida fora do sistema. Portanto, há uma adesão aos valores do sistema na vida, levando as pessoas a sentirem-se protegidas e seguras. Elas sobrevivem por integrarem-se totalmente, identificando-se e adequando-se às exigências que the são impostas, como garantia de sua permanência na empresa.

Para o contexto no qual a pesquisa foi realizada, o modelo Golem Laborioso, é bem adequado, pois é garantido para a empresa que as pessoas mantenham uma postura semelhante umas às outras, desenvolvam suas atividades e ajam na organização dentro das normas e procedimentos por ela aceitos. Assim, os trabalhadores anulam sua individualidade, vivem uma vida restrita à vida da organização, fazendo dos valores da organização os seus valores pessoais. São trabalhadores com uma adesão total ao sistema, que não se imaginam fora desse contexto, uma vez que essa foi a primeira vivência profissional, a realidade que lhes foi apresentada e já conhecem bem a modalidade de trabalho, remetendo a metáfora da Alegoria da Caverna de Platão.

\section{DISCUSSÃO E CONSIDERAÇÕES FINAIS}

Foi possível perceber que o momento da pesquisa permitiu aos participantes refletirem a respeito de determinados assuntos relacionados a sua vida e sua postura no trabalho.

Durante a realização da pesquisa, pôde-se observar que a empresa não oferece aos funcionários melhorias nas condições de trabalho no que se refere a móveis e maquinários, não possuindo, também, nenhum investimento em tecnologia, como internet, por exemplo. A utilização da internet cria a possibilidade de as pessoas estarem conectadas com o mundo externo e a falta dela pode ser entendida como uma maneira de manter os funcionários isolados.

As promoções - e algumas concessões - são tratadas com informalidade, pois existe um discurso por parte da administração geral de que todos devem buscar 
aprimoramento acadêmico para futuras oportunidades dentro da empresa, sendo que essas circunstâncias são bem limitadas e ocasionais.

Quanto às contratações, pessoas com pouca idade e sem experiência profissional são priorizadas, mesmo em cargos técnicos, mas com exigência de uma avaliação psicológica. Essa forma de admissão pode ser pensada por duas vertentes:

A primeira seria manter os funcionários na empresa por muitos anos, pois foi identificada uma gratidão por parte dos participantes, pela oportunidade que lhes foi concedida quando não tinham experiência. Alguns, inclusive, mencionaram esse sentimento durante a entrevista, de forma emocionada.

A questão de entrar em uma empresa sem experiência e ter "ganhado" a oportunidade da primeira experiência faz com que as pessoas, em alguns casos, fiquem com uma espécie de "dívida psíquica" e a forma de pagá-la é de permanecer na empresa e trabalhar da melhor forma possível, pois sair da empresa seria percebida como uma forma de traição.

A segunda seria relaciona a admissão de pessoas sem experiência com o desconhecimento de outras realidades. A forma de trabalhar que lhes é apresentada passa a ser considerada uma verdade absoluta, até porque se acredita que as pessoas podem ser moldadas e os gestores que participaram da pesquisa acabam sendo modelos e referências para essas pessoas que não possuem vivência profissional.

Nos casos pesquisados, ficou evidenciado que os profissionais se apegam aos seus trabalhos e se acostumam com a realidade que lhes é apresentada. Muitas vezes, dão significado ao que está acontecendo à sua volta como forma de convencerem a si mesmos que se manterem por longos anos às pressões impostas pela organização da qual fazem parte foi a escolha correta. Afinal, sair da empresa seria arriscar-se no desconhecido, o que poderia gerar sofrimento, perigo e ameaça

Sair da empresa, para os participantes desta pesquisa, seria como romper um laço vital da própria existência, o que leva a crer que, mesmo quando o trabalho se torna insuportável, o trabalhador busca estratégias para subsistir a ele.

Por tais motivos, conclui-se que as pessoas não se sentem livres para proporem e desenvolverem novas formas de encarar e enxergar as situações que 
Ihe são apresentadas na organização e ficam aprisionadas aos seus trabalhos por terem dificuldades em enfrentar riscos de uma nova realidade. Os indivíduos tendem a criar suas próprias histórias de vida e a viverem como prisioneiros das tramas pessoais que eles mesmos desenvolvem.

\section{REFERÊNCIAS}

BENDASSOLLI, P. F. Críticas às apropriações psicológicas do trabalho. Revista Psicologia e Sociedade, Belo Horizonte, v. 23, n. 1, p.75-84, 2011.

COSTA, I. S. A. Poder/saber e subjetividade na construção do sentido do teletrabalho. 2003. 124 f. Tese (Doutorado em Administração) - Escola Brasileira de Administração Pública de Empresas (Ebape), Fundação Getúlio Vargas (FGV), Rio de Janeiro, 2003.

DAVEL, E.; VERGARA, S. C. (Org.). Gestão com pessoas e subjetividade. São Paulo: Atlas, 2006.

DEJOURS, C. Subjetividade, trabalho e ação. Revista Produção, Florianópolis, v. 14, n.3, p. 27-34, 2004.

DEPARTAMENTO INTERSINDICAL DE ESTATÍSTICA E ESTUDOS SOCIOECONÔMICOS. DIEESE. Anuário dos trabalhadores. Disponível em: $<$ http://www.dieese.org.br>. Acesso em: 03 jun. 2012.

DEPARTAMENTO INTERSINDICAL DE ESTATÍSTICA E ESTUDOS SOCIOECONÔMICOS. Rotatividade e flexibilidade no mercado de trabalho. São Paulo, 2011. Disponível em: <http://www.dieese.org.br>. Acesso em: 03 jun. 2012.

ELIADE, M. Mito e realidade. São Paulo. Perspectiva, 2013.

ENRIQUEZ, E. A organização em análise. Petrópolis: Vozes, 1997.

FREUD, S. O mal-estar na civilização [1927/1931]. Rio de Janeiro: Imago, 1974.

FREITAS, M. E. Contexto social e imaginário organizacional moderno. Revista de Administração de Empresas - ERA, São Paulo, v. 40, n. 2, p. 6-16, 2000.

MENDES, G. O desejo de conhecer e o conhecer do desejo: mitos de quem ensina e de quem aprende. Porto Alegre: Artes Médicas, 1994. 
MEYRINK, G. O Golem. São Paulo: Hemus, 2003.

MORGAN, G. Imagens da organização. São Paulo: Atlas, 1996.

PAGÈS, M. et al. O poder nas organizações. São Paulo: Atlas, 2006.

REY, F. G. Pesquisa qualitativa e subjetividade: os processos de construção da informação. São Paulo: Pioneira Thomson Learning, 2005.

O social na psicologia social: a emergência do sujeito. Petrópolis: Vozes, 2004.

Sujeito e subjetividade: uma aproximação histórico-cultural. São Paulo:

Pioneira Thomson Learning, 2003.

THIRY-CHERQUES, H. R. Modelos de sobrevivência como meios de contracolonização em processos produtivos. Tese (Doutorado em Engenharia de Produção) - Coordenação de Pós-Graduação de Engenharia, Universidade Federal do Rio de Janeiro, Rio de Janeiro, 2000.

. Sobreviver ao trabalho. Rio de Janeiro: FGV, 2004.

VERGARA, S. C. Métodos de pesquisa em administração. 2. ed. São Paulo: Atlas, 2006.

VIANA, E. A. S. Sentido do trabalho: discurso dos trabalhadores de uma organização do terceiro setor em Belo Horizonte. 2008. 183 f. Dissertação (Mestrado em Administração) - Programa de Pós-Graduação em Administração, Faculdade Novos Horizontes, Belo Horizonte, 2008. 